\title{
The requirements for implementing Sustainable Development Goals (SDGs) and for planning and implementing Integrated Territorial Investments (ITI) in mining areas
}

\author{
Lucyna Florkowska, ${ }^{1, *}$, and Izabela Bryt-Nitarska ${ }^{1}$ \\ ${ }^{1}$ Polish Academy of Sciences, The Strata Mechanics Research Institute, Cracow, Poland
}

\begin{abstract}
The notion of Integrated Territorial Investments (ITI) appears more and more frequently in contemporary regional development strategies. Formulating the main assumptions of ITI is a response to a growing need for a co-ordinated, multi-dimensional regional development suitable for the characteristics of a given area. Activities are mainly aimed at improving people's quality of life with their significant participation. These activities include implementing the Sustainable development Goals (SDGs).

Territorial investments include, among others, projects in areas where land and building use is governed not only by general regulations (Spatial Planning and Land Development Act) but also by separate legal acts. This issue also concerns areas with active mines and post-mining areas undergoing revitalization. For the areas specified above land development and in particular making building investments is subject to the requirements set forth in the Geological and Mining Law and in the general regulations. In practice this means that factors connected with the present and future mining impacts must be taken into consideration in planning the investment process.

This article discusses the role of proper assessment of local geological conditions as well as the current and future mining situation in the context of proper planning and performance of the Integrated Territorial Investment programme and also in the context of implementing the SDGs. It also describes the technical and legislative factors which need to be taken into consideration in areas where mining is planned or where it took place in the past.
\end{abstract}

Keywords: mining areas, mining damage, buildings, Sustainable development Goals (SDGs), Integrated Territorial Investments (ITI)

* Corresponding author: florkowska@img-pan.krakow.pl 


\section{Introduction}

The effectiveness of a socio-economic policy in achieving economic growth goals greatly depends on being able to properly assess and make provisions for local conditions, which can have a significant influence on shaping the environmental, technical, economic and social aspects of life in a given area. This is why local conditions should be used to determine the framework and directions for proper task planning and implementation.

Mining areas - rich in natural resources, and for this reason subject to strong anthropopressure - are regions of very specific nature. This special character can be seen in many areas of socio-economic life. This paper points out and describes the specificity in terms of geotechnical and structural conditions of planning, erecting and using buildings in the aspect of compatibility with the sustainable development goals and of SDGs implementation tools.

The specific nature of the geotechnical and technological requirements for erecting buildings in mining areas has a significant impact on the technical and economic aspects of construction projects. This special nature also applies to the safe use of buildings and infrastructure. For this reason appropriate shaping of a socioeconomic policy requires the use of research findings in elaborating and implementing procedures which impose both the obligation to use appropriate geotechnical and structural solutions in building construction and the obligation to exploit deposits in such a way that damage is minimized and failures and disasters can be prevented.

\subsection{Sustainable Development Goals (SDGs)}

Managing natural resources in a way that minimises the damage caused by their use, limits the transformation of natural ecosystems and saves some of these resources for future generations is not only an ethical but also a legal requirement. Sustainable development is generally accepted as the idea of achieving a harmonious improvement in the standard of living and scientific, technical and economic advancement at the same time protecting the environment and natural resources and bearing in mind the needs of future generations. The idea of sustainable growth has been transformed from a theoretical doctrine into a system of legal regulations which aim to shape social and economic changes in the world [1].

In September 2015 the international Sustainable Development Summit was held in New York, whose goal was to develop a new, global development strategy until 2030. This strategy was supposed to continue, but also to expand, the activities undertaken to achieve the Millennium Development Goals (MDGs) adopted in UN Millennium Declaration in 2000. One hundred UN member states, including Poland, signed the summit's final

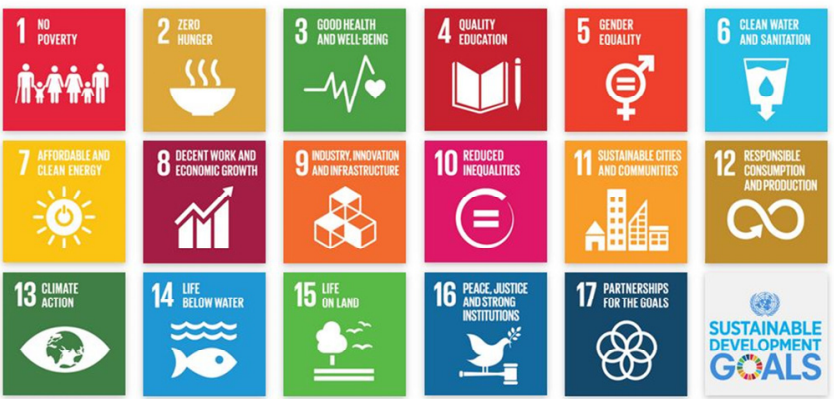

Fig. 1. Sustainable Development Goals - SDGs (http://www.un.org/sustainabledevelopment/sustainable-developmentgoals/) document called

"Transforming Our World: the 2030 Agenda for Sustainable Development".

The 2030 Agenda lists 17 main Sustainable Development Goals (SDGs) with allocated operational targets specifying ways of achieving them (fig. 1). They make up a list 
of 169 agreed global solutions, which should be reflected on national and regional levels in actions undertaken with local conditions in mind.

Poland, as a signatory of the Agenda, is obliged to make efforts to achieve the set goals, adjusting the scope of actions undertaken to the situation in respective regions. In Poland legal requirements concerning the implementation and enforcement of sustainable development principles are regarded as important. Article 5 of the Constitution of the Republic of Poland states that the Republic of Poland shall follow the principle of sustainable development. The national sustainable economic, environmental, social, administrative and political development will be implemented through relevant statutory regulations. Also, a number of strategic documents were drawn up, which determine the so called development policy as well as the principles of monitoring its progress [2].

\subsection{Integrated Territorial Investments (ITI)}

Integrated Territorial Investments are one of the tools used to implement sustainable development goals. They are mainly concerned with sustainable development of urban areas. Both because of the areas where they are to be implemented and the kind of actions to be undertaken, ITI can be especially beneficial in mining areas. The area of ITI activities overlaps with areas affected by mining, which are usually also highly industrialized and urbanized. In Poland the Upper Silesian Coal Basin is one such area, where large urban agglomerations are affected by the impact of repeated underground mining operations and where numerous degraded areas can be found. According to a document called "The principles of implementing Integrated Territorial Investments in Poland" (The Ministry of Regional Development, Warsaw 2013) one of the main directions of actions undertaken under the ITI programme is "Restoring the socio-economic functions in devastated urban areas". The first ITI-funded projects were carried out in the Silesian region. The ITI initiative is being implemented there in the so called Central Sub-region, where funding was granted among others to brownfield area revitalisation projects. Restoring functional value to devastated areas, especially in the context of turning postmining areas into investment areas, is a problem which requires specialist knowledge. To carry out such undertakings effectively, solutions should be in place to ensure the permanence of the results, the safety of buildings erected in the revitalized area and measures against increased wear of buildings and infrastructure. This is why the procedures of granting funding under the ITI framework should include the requirements of carrying out relevant tests of the state of the subsoil, analyses of the geotechnical and mining situation and of applying appropriate technical solutions. To ensure that the above requirements are fulfilled project funding applications should be verified by experts who have the knowledge of the impact that subsoil deformations can have on buildings. Due to local conditions in which additional loads are generated by mining any construction project in mining areas must fulfil additional requirements. Meeting these requirements should be obligatory for any investment project carried out as part of the ITI programme.

\section{The specific character of mining areas}

The specific character of mining areas can be seen in many aspects of social and economic life. The characteristic feature of mining areas is the so called mining damage and the existence of degraded areas of no functional value $[3,4]$.

The term mining damage is used to describe damage caused by the operation of a mining facility. In practice, this term is used mainly in the context of changes to the morphology and hydrological conditions, of dynamic events with the characteristics of tremors and of the impact these processes and phenomena have on buildings $[5,6]$. 
However, in the light of the above definition, negative changes in the environment (including changes in air quality) caused by dust and gas emission to the atmosphere as well as water and soil pollution (including salinity) which accompany the exploitation of solid minerals and fluidized deposits should also be treated as mining damage. These direct effects of mining bring about wider economic, social and environmental phenomena known as the effects of mining damage (Fig. 2)[4].

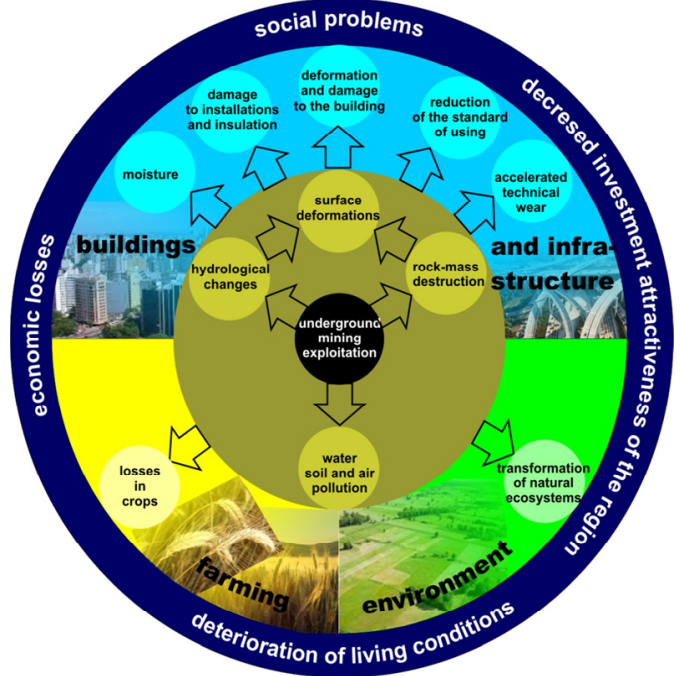

Fig. 2. The impact of underground mining exploitation on the surroundings [4]
In the material aspect negative effects of mining manifest themselves as:

- the destruction of rock mass structure in the proximity of the excavation,

- surface deformations above the excavation,

- hydrological changes,

- deformations and damage to buildings, civil engineering structures and technical infrastructure,

- an increased wear of buildings, civil engineering structures and technical infrastructure,

- air and soil pollution.

Examples of significant damages created in building construction elements due to the effect of loosening of a ground caused by mining operations are presented in Fig. 3. In the cases presented, there was a loss of load-bearing capacity of the construction elements, combined with a threat to the safety of building. These damages were revealed in the buildings due to the movement of the mining operations front beneath them.


Fig. 3. Cracks in load-bearing walls due to loosening of a ground caused by mining mining floor dislocations [4] 
Fig. 4a shows an example of a building that was in the range of the impact of the outcrops of the active fault of the geological layers. Activation of the fault zone was triggered by mining exploitations, which in several subsequent seams undermined the dislocation plane. As a result of repeated exploitation of the deposit in the vicinity of an active geological fault, in the building the damage occurring during subsequent years led to the necessity of excluding it from use and for demolition, despite taking protections and repairs (Fig. 4b)
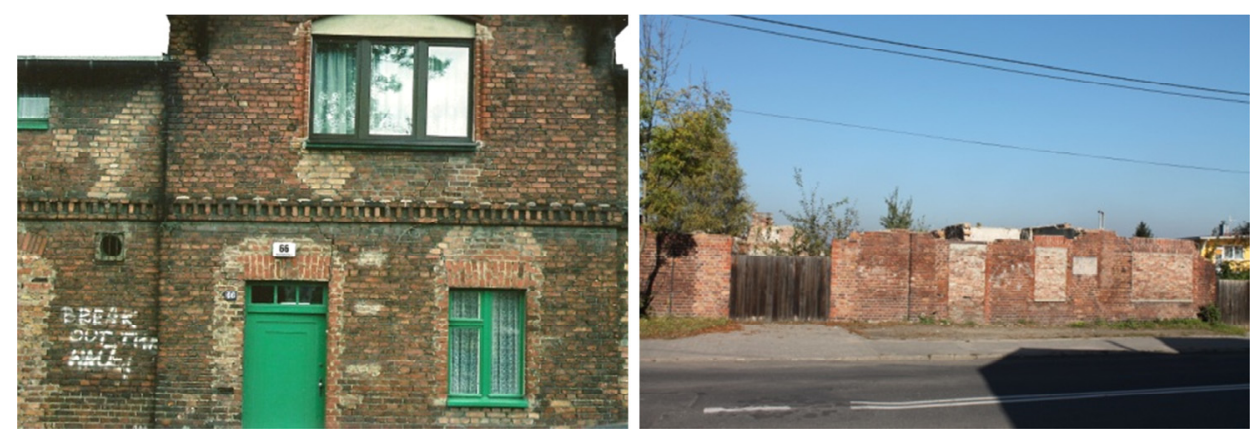

Fig. 4. Damage of a building on the convex periphery of the mining trough, while the impact of terrain threshold a) cracking of the front wall - condition for 2002 , c) condition of the building in 2014

From the kinds of mining damage mentioned, the damage which occurs in buildings and infrastructure is definitely the most apparent and causes the greatest problems for the people living in areas affected by mining. Deformations and damage to buildings, roads and utilities (power, gas, water supply, sewerage, heating and communications) cause problems with using them and/or put the safety of these structures at risk bringing about economic and social consequences both locally (owners and users) and globally - influencing the general condition of the area and its inhabitants.

Material mining damage causes unavoidable economic consequences. These consequences affect both the mining company itself but also the owners and users of property and buildings exposed to mining impact. The cost of protection and strengthening devices along with minor and major repairs are the main economic consequences of mining damage for property owners and users. A general economic consequence is the property's decreased value due to both increased technical wear of the building and the fact that the property stands on land threatened with further ground deformations $[4,7]$.

\section{Local technical requirements for mining areas}

From the point of view of planning and carrying out technical projects, the key fact is that in areas exposed to the impact of mining the structural components of buildings must bear additional loads caused by deposit exploitation. The additional requirements resulting from this have been imposed by relevant legal regulations. As early as at the project planning stage a special approach to design making is necessary for mining areas. According to the Decision of the Minister of Transport, Construction and Maritime Economy on the detailed scope and form of building permit design of 25 April 2012 (Journal of Laws of 27 April 2012, item 462) the site development plan (which is an integral part of the building permit design) in its descriptive part should contain "data specifying the impact of mining on the site of the planned construction undertaking situated within the borders of a mining 
area" ( $\S 8.2$, p.6), and the technical description of the design should include "the geotechnical category of the building/structure, the conditions and method of laying its foundations and of securing it against the impacts of mining” (§11.2 p.4).

One of the fundamental aspects of design making is determining the geotechnical category of the building. According to the Decision of the Minister of Transport, Construction and Maritime Economy on the detailed scope and form of a building permit design of 25 April 2012 (Journal of Laws of 27 April 2012, item 463) on determining the geotechnical conditions of laying foundations of buildings/structures complicated subsoil conditions exist "in the case of subsoil strata affected by adverse geological phenomena, in particular processes and forms connected with carstification, landslides, scouring, quicksand, glacial tectonics, expansive and subsidence-prone soils; situated in mining damage areas with possible discontinuous rock mass deformations, in river valleys and deltas as well as in sea areas".

According to the classification used in Eurocode 7 (PN-EN 1997 Geotechnical designs) a building erected in mining areas belongs to the third geotechnical category, which comprises among others "buildings/structures in areas with a high probability (...) of longterm subsoil movements" (chapter 2.1).

According to the Decision of the Minister of Infrastructure of 12 April 2002 on the technical conditions that buildings and their location should meet (Journal of Laws no. 75 , item 690) mining-induced damage belongs to negative impacts which restrict the possibility of erecting buildings intended for human occupancy in areas affected by it; $\S 11.1$ sets forth that the condition which must be fulfilled if a building is to be erected in the area affected by such negative impacts is the use of technical means mitigating the negative effects or increasing the building's resistance to these impacts. "Measures to secure the structure of a building appropriate for the type of threat resulting from anticipated mining impact, which is understood as constrained displacements, deformations and tremors of the subsoil must be used in areas affected by mining impact" ( $(205)$. The Decision also contains an exception concerning the fulfilment of the serviceability limit states (SLS) criteria for "these deformations, damage and tremors of the structure which result from impacts caused by mining” (§ 204.6).

To properly design protections for a building at risk of mining damage additional construction requirements must be fulfilled to meet the requirement of securing the structure against dangerous subsoil deformations. When designing a building situated in a mining area, one must also remember to meet all the requirements specified in relevant regulations. When formulating the assumptions for calculations it is worth bearing in mind that:

1. The values of land deformation indexes which are found in a forecast refer to the state which is the state of the surface at the moment immediately preceding making the forecast and are valid only for the part of mining included in the mining operation plan (MOP) for several years.

2. In the vast majority of mining areas mineral exploitation has lasted for a long time, which has caused the original rock mass structure to be significantly disturbed, and can increase the extent and magnitude of surface deformations.

3. When designing a building in an area where many panels were mined in several (sometimes more than ten) seams, it is a mistake to omit this fact and fail to recognize the possibility that old goaf can be activated or mining effects can overlap [8].

\section{Summary}

When situating economic undertakings in mining and post-mining areas important local conditions must be taken into consideration. They play a special role in construction 
projects and in revitalization projects to restore degraded areas. As areas where deposit mining takes place are especially under threat due to strong anthropopressure, it is very important to properly recognize and make allowances for local conditions and requirements for sustainable development actions to be effective.

Meeting additional requirements resulting from surface and development protection requirements is in the interest of the mining municipalities, property owners, investors and mining enterprises. A regular implementation of structural and geotechnical protection to secure buildings erected in mining areas will minimize the risk of failure and disasters, reduce an increased technical wear of buildings and minimize disputes and conflicts. The purpose of additional requirements in terms of using an extended assessment of the geological and mining situation, adjusting construction solutions to the stricter requirements, providing appropriate structural and geotechnical protection or installing building monitoring systems is to reduce the extent of the damage and at the same ensure better durability of undertakings (Fig. 5). This is why additional steps should be taken for these requirements to become obligatory in mining areas, for example by incorporating them into relevant areas at the level of making a zoning plan and in the case of state or EUfunded projects, including those carried out under the ITI framework.

\begin{tabular}{|l|} 
STRUCTURAL PREVENTION OF MINING DAMAGE: \\
\hline choosing an appropriate building shape \\
\hline constructional designing taking into account mining influences \\
\hline providing additional elements to strengthen the structure \\
\hline makrying out installation and insulation works properly \\
\hline geotechnical protection \\
\hline technical supervision of construction stages \\
\hline expert supervision during strong mining impact \\
\hline predicting and diagnosing the state of the building using numerical simulations \\
\hline monitoring the state of the building using measuring systems \\
\hline
\end{tabular}

Fig. 5. Elements of structural prevention as important additional local requirements for mining areas [4]

\section{References}

1. K. Górka, Gospodarka w Praktyce i Teorii. I. 3(36), pp. 34-50 (2014)

2. L. Florkowska, Zesz. Nauk. I GSMiE PAN, pp. 105-117 I. 94, (2016)

3. L. Florkowska, Arch. of Min. Sc., V. 55, pp. 691-701 (2010)

4. L. Florkowska, I. Bryt-Nitarska, A. Maj, Mining damage in buildings. Kraków: Arch. of Min. Sc. Monography. I. 17. (2016)

5. L. Florkowska, I. Bryt-Nitarska, Przegląd Górniczy, 71(11), pp. 101-105 (2015)

6. O. Kaszowska, "The Environment protection in mining areas". pp. 189-209 (2006)

7. I. Bryt-Nitarska, Zesz. Nauk. I GSMiE PAN, issue 94, pp. 119-125 (2016)

8. L. Florkowska, J. Walaszczyk, J. Cygan, Prace IMG PAN, T.14, I.1-2, p.93-102(2012)

9. Transforming our world: the 2030 agenda for sustainable development. 2015. A/res/70/1 United https://corporate-citizenship.com 